Gut, 1976, 17, 975-983

\title{
Intravenous administration of diazepam in patients with chronic liver disease
}

\author{
R. A. BRANCH ${ }^{1}$, M. H. MORGAN, J. JAMES, AND A. E. READ \\ From the Departments of Medicine and Pharmacology, University of Bristol, Bristol
}

SUMMARY The EEG response and drug kinetics after intravenous infusion of diazepam at $1.0 \mathrm{mg} /$ min until nystagmus, dysarthria, and moderate sedation developed, has been investigated in five normal subjects and 17 patients with chronic liver disease. Diazepam induced adequate premedication with a similar clinical response in all subjects with no adverse reactions. Maximal response was during or within five minutes of infusion. The dose of diazepam required in chronic liver disease was $17.9 \pm 1.4 \mathrm{mg}(\mathrm{M} \pm \mathrm{SEM})$ compared with $27 \pm 5.4 \mathrm{mg}$ in controls $(\mathrm{P}<0.01)$. Dose correlated significantly with serum albumin $(P<0.05)$. Baseline mean dominant frequency $(\mathrm{MDF})$ and slow wave index (SWI) significantly correlated with albumin $(P<0.01)$. After diazepam, the MDF decreased and SWI increased. The change was greatest at the time of maximal clinical response. It was greater in liver disease and was greatest in patients with previous hepatic encephalopathy. In spite of reduced dose requirements in liver disease, there was no significant difference in plasma concentration at the end of drug infusion. This might in part be explained by a significant dose dependent increase in volume of distribution $(P<0.01)$. Differences in EEG response at similar plasma concentrations suggested differences in cerebral sensitivity. The clearance of diazepam decreased in chronic liver disease and correlated with the serum albumin $(P<0.01)$ and also with the clearances of antipyrine $(\mathrm{P}<0.001)$ indocyanine green $(\mathrm{P}<0.001)$ and d-propranolol $(\mathrm{P}<0.001)$.

Diazepam (Valium) has established a well deserved reputation for being a safe and effective drug when used as premedication for patients undergoing potentially unpleasant practical procedures which require their cooperation. After intravenous administration it causes an almost immediate anxiolytic effect, followed at higher doses by ptosis, nystagmus, dysarthria, and sedation. When the rate of injection is slow the maximum effect is noted within a short period of the end of drug infusion. The limited duration of effect is ideal for short procedures, and has an added advantage of a subsequent short period of mild sedation and amnesia.

Patients with chronic liver disease, particularly those with a tendency to develop portasystemic or hepatic encephalopathy (PSE), are known to be unduly sensitive to many psychotropic drugs (Read et al., 1969; Morgan and Read, 1972). However, it has been suggested that diazepam does not cause undue sedation in such patients (Murray-

\footnotetext{
'Present address: Division of Clinical Pharmacology, Department of Pharmacology, Vanderbilt University, School of Medicine, Nashville, Tennessee 37232, USA.

Received for publication 3 August 1976
}

Lyon et al., 1971). The present study was prompted by observations on one patient with chronic liver disease, who after a small intravenous dose of diazepam developed marked sedation lasting for an extended period. This suggested that either the patient was unduly sensitive to diazepam, or else that the disposition of the diazepam had been altered so that more drug was available for a longer time for its pharmacological action. The problem was investigated by comparing responses of normal subjects and patients with chronic liver disease to intravenous administration of diazepam.

\section{Methods}

\section{SUBJECTS}

Five normal subjects and 17 patients with histologically proven chronic liver disease consented to take part in the investigation. Routine clinical examination and biochemical liver function tests were accompanied by a full drug history. Night sedation with nitrazepam on the night preceding the test day was allowed, but other psychotropic drugs were avoided. Patients with acute liver disease, acute complications of chronic liver disease, evidence 
of biliary obstruction, and those receiving drugs known to induce hepatic microsomal enzymes were excluded.

Clinical diagnoses of the 17 patients were alcoholic cirrhosis (seven), chronic active hepatitis (six), cryptogenic cirrhosis (three), and scleroderma (one). Seven of the patients had previous episodes of PSE, and one patient had evidence of mild encephalopathy at the time of the study. Seven patients had ascites. Five patients had both ascites and a history of PSE.

\section{DIAZEPAM ADMINISTRATION}

In all subjects diazepam (Valium, Roche) was administered intravenously at a constant rate of $1 \mathrm{mg} / \mathrm{min}$. This slow rate of infusion was adopted in this experimental protocol to allow continuous assessment of the subject to be made during the infusion. The subject was maintained in conversation throughout drug infusion, apart from the time during which the EEG was recorded. The infusion was stopped when the subject developed ptosis, nystagmus, dysarthria, and a degree of sedation from which arousal was becoming difficult to achieve. This clinically judged endpoint was one considered to be optimal for premedication before a practical procedure. In each case the endpoint was decided by a consensus of the same two observers throughout the study.

\section{EEG METHOD}

Five 15 second periods of EEG activity were recorded from bipolar electrodes situated over the temporal and occipital areas of the non-dominant hemisphere. The subjects lay with eyes closed and jaw relaxed. Considerable care was taken to prevent any of the subjects from falling asleep. Records were stored on magnetic tape, and subsequently analysed by the technique originally described by Laidlaw and Read (1963), and Read et al. (1969). This method allows calculation of the mean dominant frequency (MDF) and slow wave index (SWI).

Two records were taken before drug administration, at five minute intervals during drug infusion, then at five, 15, 30, 60, 90, and 120 minutes after the end of infusion.

\section{DIAZEPAM KINETICS}

Heparinised venous blood samples were drawn from an indwelling needle situated in a peripheral vein in the opposite arm to the site of drug infusion, before diazepam administration, at the end of the infusion, then at 15, 30, 60 minutes, three, six, 10,21, 29, 45 , and 54 hours after the end of diazepam infusion. The plasma was separated and stored at $-20^{\circ} \mathrm{C}$ until assayed by a gas chromatographic procedure, using medezepam as an internal standard. The diazepam was extracted by the method of Klotz et al. (1975), $2 \mu$ l ether concentrate was injected into a Pye series 104 chromatograph equipped with a tritium electron capture detector. A Pyrex glass column was packed with $1.5 \%$ OV-17 coated on Chromosorb G 100/200 mesh. Operating conditions were: oven temperature $250^{\circ} \mathrm{C}$, detector temperature $300^{\circ} \mathrm{C}$, and nitrogen flow rate $50 \mathrm{ml} / \mathrm{min}$. All samples were run in duplicate and averaged. This method specifically measures parent drug; in particular desmethyl diazepam is clearly separated by the column.

The concentration of diazepam was obtained by measuring the peak area (peak height $x$ width at half peak height) of diazepam and medezepam. The peak area ratio was then compared with previously constructed calibration curves over a concentration of $1-50 \mathrm{ng} / \mathrm{ml}$.

\section{ANTIPYRINE KINETICS}

All subjects received $1200 \mathrm{mg}$ oral antipyrine after an overnight fast. Multiple peripheral venous blood samples were taken over the subsequent three to 100 hours. Antipyrine was assayed by the method of Brodie et al. (1949).

\section{INDOCYANINE GREEN KINETICS}

All subjects received $0.5 \mathrm{mg} / \mathrm{kg}$ body weight of indocyanine green as a rapid intravenous bolus. Peripheral blood samples were obtained through an indwelling needle at three minute intervals for 21 minutes in normal subjects and up to 90 minutes in patients with severe chronic liver disease. Plasma concentrations were estimated by the method of Caesar et al. (1961).

\section{D-PROPRANOLOL KINETICS}

All subjects received $40 \mathrm{mg}$ d-propranolol over five minutes by intravenous infusion. Peripheral blood samples were taken over 12 hours in normal subjects and up to 48 hours in patients with chronic liver disease. Whole blood samples were assayed by the method of Shand et al. (1970).

\section{KINETIC ANALYSIS}

Clearance for each drug was estimated from:

$$
\text { Clearance }=\frac{\text { Dose }}{\text { AUC }}
$$

where AUC is the area under the plasma or blood concentration time curve calculated using the trapezoidal rule and extropolating the terminal exponential to infinity.

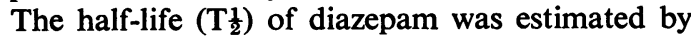
least square regression analysis of the terminal log 
plasma concentration-time curve. Volume of distribution (Vd) was calculated from:

$$
\mathrm{Vd}=\frac{\mathrm{Cl} \times \mathrm{T}_{2}^{1}}{0.693}
$$

Dose, clearance, and volume of distribution have been normalised for body weight.

\section{Results}

\section{CLINICAL DETAILS}

Diazepam induced relaxation, sedation, ptosis, nystagmus, and dysarthria in all subjects tested. At the clinical endpoint of the infusion there were no distinguishing features between normal subjects and patients. The dose of diazepam required to induce this common endpoint was $27 \pm 5.4 \mathrm{mg}$ in normal subjects and $17.9 \pm 1.4 \mathrm{mg}$ in patients with chronic liver disease $(P<0.01)$. Adequate medication for practical procedures was maintained for at least 45 minutes in all subjects. Peak clinical effect occurred either at the end or within five minutes of stopping the infusion. After drug administration all subjects showed a degree of mild sedation extending for up to 48 hours. In no case was this prolonged effect associated with any other adverse reaction, and in no instance did the clinical progress of a patient give rise to concern.

The EEG record of one patient was relatively featureless and therefore unsuitable for analysis of the MDF, though the SWI could be analysed. The serum albumin correlated with the dose of diazepam required to induce a similar clinical endpoint in response (Fig. 1) and with the EEG parameters of MDF and SWI before drug administration (Fig. 2). In addition, the dose of diazepam correlated with base line SWI (Table 1). Maximal change of the EEG parameters occurred at the time of peak clinical response either during the infusion or within five minutes of its end. At the time of maximal change both MDF and SWI correlated significantly with both the serum albumin and the dose of diazepam administered (Table 1). In spite of significant correlations between baseline EEG parameters and the serum albumin, the baseline EEG parameters in normal subjects were not significantly different from baseline EEG parameters in patients with or without a preceding history of PSE (Fig. 3). The similar baseline EEG allowed a valid comparison of responses to diazepam (Table 2). In normal subjects (group A), at the time of maximal EEG response there was no change in MDF, but there was a small significant increase in SWI $(P<0.05$ paired Student's $t$ test). In patients with chronic liver disease without a preceding history of PSE (group B), there was a significant decrease in MDF $(\mathrm{P}<0.001)$ and $a$

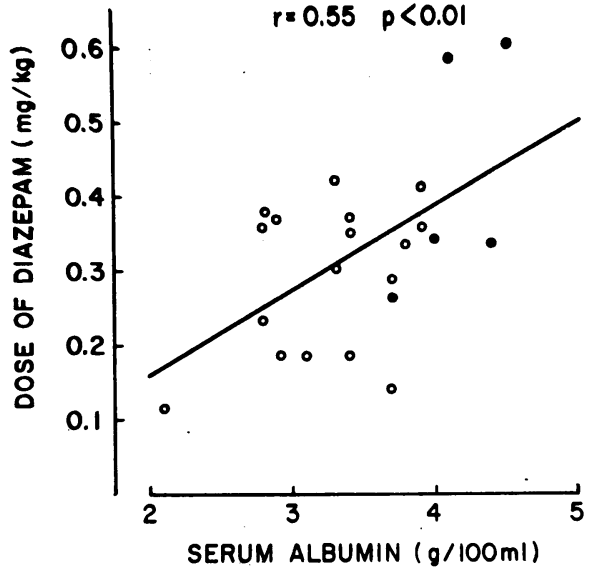

Fig. 1 The relationship between the dose of diazepam per $\mathrm{kg}$ body weight required to induce a constant defined clinical response and the serum albumin in five normal subjects (O) and 17 patients with chronic liver disease $(\bigcirc)$.

greater increase in SWI $(\mathrm{P}<0.001)$. In patients with chronic liver disease and past history of PSE (group C) the changes were similar but were significantly greater.

After drug administration, the return of MDF and SWI to normal was longest in patients in group C (Table 2).

Certain consistent visually apparent but not quantified changes in the EEG were observed after diazepam administration. The alpha background activity was reduced and generalised low to moderate amplitude fast or beta activity (greater than $13 \mathrm{H}_{\mathrm{z}}$ ) was seen throughout the recording.

\section{DIAZEPAM KINETICS}

At the end of drug infusion, there was a wide variability in plasma concentration of diazepam which did not correlate with dose and did not significantly differ when normal subjects were compared with patients with liver disease with or without fluid retention (Table 3 ). The early high plasma concentrations of diazepam had an initial rapid decline. Between one to 10 hours after the infusion there were fluctuating plasma concentrations with most subjects having a trough between two and six hours. After this, the late phase of the plasma decay curve was exponential (Fig. 4). In patients with chronic liver disease without clinical evidence of fluid retention, the half-life of diazepam was similar to normal subjects. However, this was significantly increased in patients with ascites and oedema (Table 3). The volume of distribution showed 

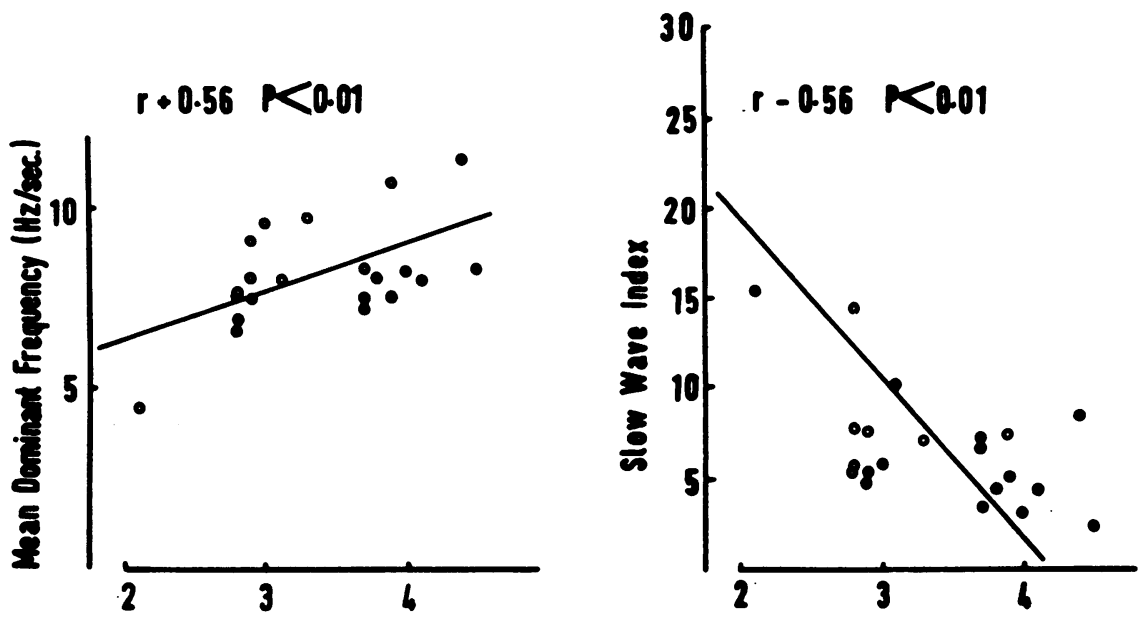

Serum Albumin $(\mathrm{g} / 100 \mathrm{ml})$
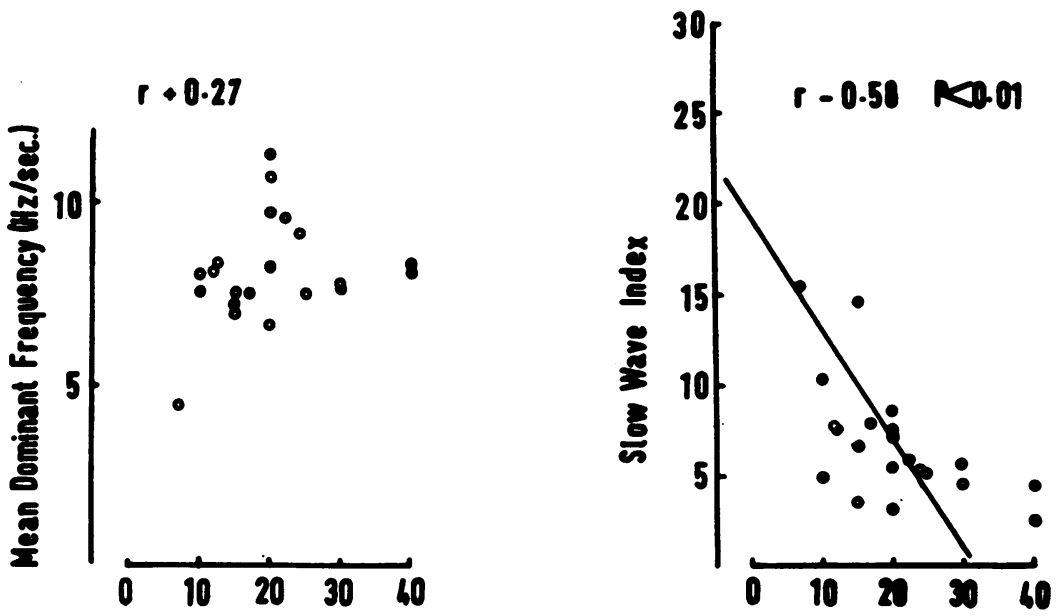

Dose of Dizzepam ( $\mathrm{mg})$

Fig. 2 The relationship between the baseline mean dominant frequency and slow wave index derived from the EEG before drug administration and the serum albumin and the dose of diazepam required to induce a constant defined clinical response in five normal subjects $(O)$ and 17 patients with chronic liver disease $(O)$. (The EEG of one patient with chronic liver disease was unsuitable for analysis of $M D F$ ).

Table 1 Correlations between EEG parameters of mean dominant frequency and slow wave index, before and at time of maximal EEG change and serum albumin and dose of diazepam required to induce similar clinical degree of premedication in five normal subjects and 16 patients with chronic liver disease

\begin{tabular}{llllll}
\hline & \multicolumn{2}{l}{ Mean dominant frequency } & & \multicolumn{2}{l}{ Slow wave index } \\
\cline { 2 - 3 } \cline { 5 - 6 } & Before drug therapy & At maximal response & & Before drug therapy & At maximal response \\
\hline Serum albumin & $+0.56^{*}$ & $+0.66^{*}$ & & $-0.56^{*}$ & $-0.65^{*}$ \\
Dose of diazepam & +0.27 & $+0.44^{*}$ & $-0.58^{*}$ & $-0.70 \dagger$ \\
\hline
\end{tabular}

$P<0.05^{*}<0.001 \dagger$ 

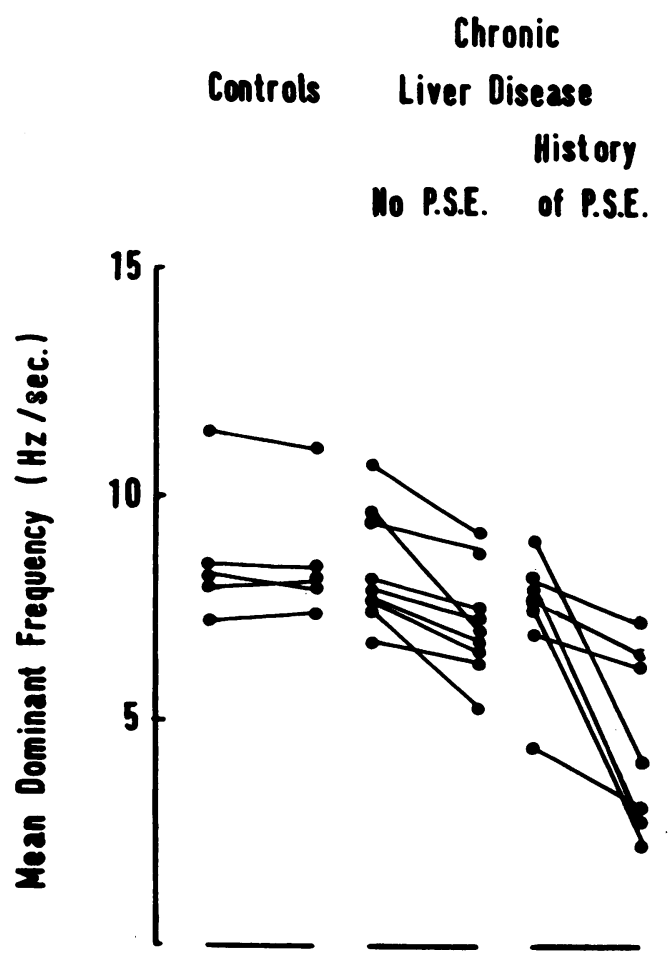
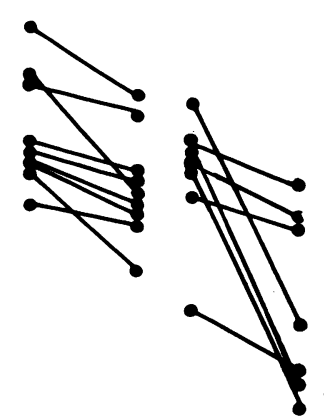

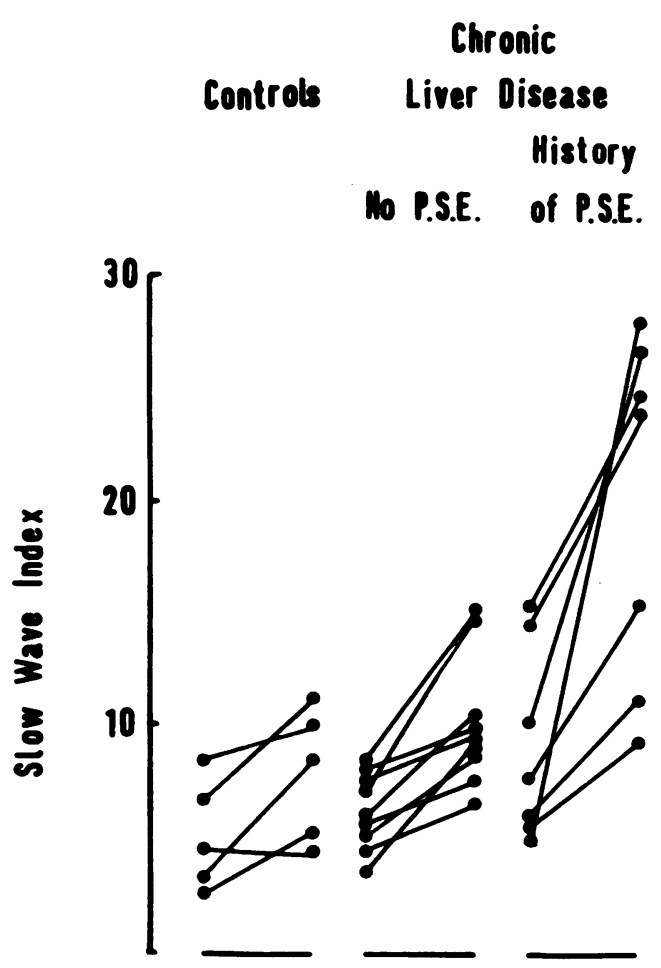

Fig. 3 The mean dominant frequency and slow wave index before and at the time of maximal EEG change after an infusion of diazepam at $1 \mathrm{mg} / \mathrm{min}$ until a constant defined clinical response was achieved, in five normal subjects and 17 patients with chronic liver disease, seven of whom had had previous episodes of portasystemic encephalopathy. (The EEG of one patient with chronic liver disease was unsuitable for analysis of MDF).

Table 2 Maximal change in mean dominant frequency and slow wave index, and duration of change in slow wave index after intravenous administration of diazepam in normal subjects (group A) and patients with chronic liver disease (without or with history of previous portasystemic encephalopathy)

\begin{tabular}{|c|c|c|c|}
\hline & \multirow{2}{*}{$\begin{array}{l}\text { Normal subjects } \\
\text { Group } A n=5\end{array}$} & \multicolumn{2}{|c|}{ Chronic liver disease } \\
\hline & & Group B $n=9$ & Group $C n=7$ \\
\hline $\begin{array}{l}\text { Change in mean dominant } \\
\text { frequency }\left(\mathrm{H}_{z} / \mathrm{s}\right) \\
\text { Change in slow wave index } \\
\text { Duration of change of slow wave } \\
\text { index (min) }\end{array}$ & $\begin{aligned}-0.38 & \pm 0.11 \\
+2.76 & \pm 0.97 \\
12.0 & \pm 3.4\end{aligned}$ & $\begin{aligned}-1.08 & \pm 0.29 \ddagger \\
+4.06 & \pm 0.73 \\
23.4 & \pm 3.9\end{aligned}$ & $\begin{array}{l}-3.01 \pm 0.85 \ddagger^{*} \\
+11.2 \pm 2.5+\S \\
42.7 \pm 9.4 \dagger\end{array}$ \\
\hline
\end{tabular}

Mean \pm SEM $\dagger \mathrm{P}<0.05, \ddagger \mathrm{P}<0.01$ compared with normal subjects. ${ }^{*} \mathrm{P}<0.05, \S \mathrm{P}<0.01$ comparing the two groups of patients with chronic liver disease (Using Wilcoxon-White ranking test).

a trend to decrease when normal subjects, patients without fluid retention, and patients with fluid retention were compared, but this failed to reach statistical significance. The volume of distribution measured in different subjects correlated with the dose of diazepam administered $(r=+0.69$, $P<0.001$ ) (Fig. 5) but not with age; however the volume of distribution was not measured over a dose range in any individual subject. The clearance of diazepam was reduced in patients with chronic liver disease, this reduction was statistically significant in patients with fluid retention (Table 3). Diazepam clearance had significant correlations with serum albumin $(r=+0.54, \mathrm{P}<0.001)$ (Fig. 6) and the clearance of antipyrine $(r=+0.61$, $P<0.001)$, indocyanine green $(r=+0.67$, 
Table 3 Comparison of pharmacokinetic parameters of diazepam between normal subjects and patients with chronic liver disease subdivided into patients with or without clinical evidence of ascites or fluid retention at time of study

\begin{tabular}{|c|c|c|c|}
\hline \multirow[b]{2}{*}{ Number; } & \multirow{2}{*}{$\begin{array}{l}\text { Normal subjects } \\
\text { (5) }\end{array}$} & \multicolumn{2}{|c|}{ Chronic liver disease } \\
\hline & & No ascites (10) & Ascites (7) \\
\hline $\begin{array}{l}\text { Age }(\mathrm{yr}) \\
\mathrm{Wt}(\mathrm{kg}) \\
\text { Dose of diazepam }(\mathrm{mg} / \mathrm{kg}) \\
\text { Half-life }(\mathrm{h}) \\
\text { Volume of distribution }(1 / \mathrm{kg}) \\
\text { Clearance }(\mathrm{ml} / \mathrm{min} / \mathrm{kg}) \\
\text { Plasma concentration at end of }\end{array}$ & $\begin{aligned} 50.4 & \pm 6.0 \\
62.0 & \pm 2.1 \\
0.426 & \pm 0.071 \\
43 & \pm 3.2 \\
0.980 & \pm 0.184 \\
0.243 & \pm 0.050\end{aligned}$ & $\begin{array}{ll}52 \cdot 8 & \pm 4 \cdot 1 \\
59 \cdot 6 & \pm 4 \cdot 3 \\
0.289 & \pm 0 \cdot 03^{*} \\
48 \cdot 7 & \pm 12 \cdot 1 \\
0.687 & \pm 0 \cdot 141 \\
0 \cdot 178 & \pm 0.033\end{array}$ & $\begin{array}{cl}44 \cdot 0 & \pm 6.8 \\
66 \cdot 7 & \pm 6 \cdot 0 \\
0.300 & \pm 0.39 \\
77 \cdot 4 & \pm 4 \cdot 3^{*} \\
0.591 & \pm 0 \cdot 108 \\
0.090 & \pm 0.022^{*}\end{array}$ \\
\hline infusion $(\mu \mathrm{g} / \mathrm{ml})$ & $1 \cdot 1 \pm 0.26$ & $1 \cdot 1 \pm 0.23$ & $0.7 \pm 0.15$ \\
\hline
\end{tabular}

Mean \pm SEM

* $\mathrm{P}<0.05$ Student's unpaired $t$ test in comparison with normal subjects.

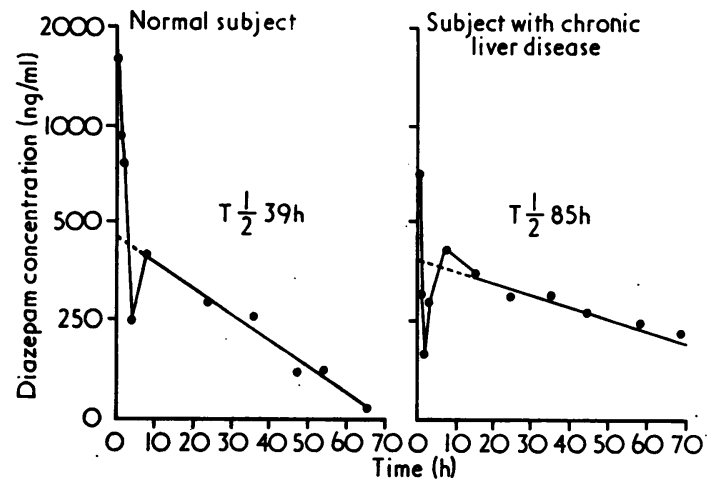

Fig. 4 Log plasma concentration-time curve of two representative subjects, a normal subject, and a patient with chronic liver disease, ascites, and a previous history of portasystemic encephalopathy.

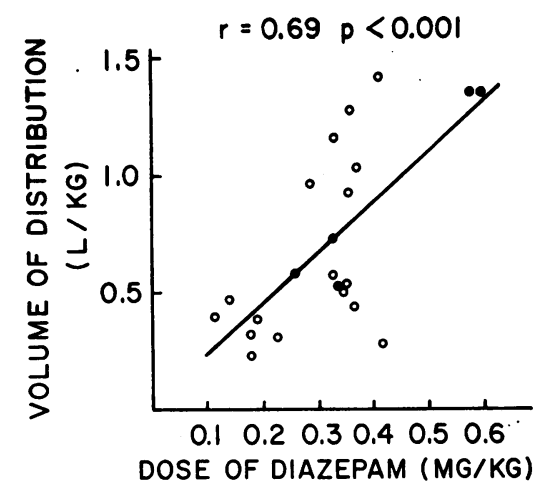

Fig. 5 The relationship between the volume of distribution of diazepam and the dose of diazepam administered by intravenous infusion at $1 \mathrm{mg} / \mathrm{min}$ in five normal subjects $(O)$ and 17 patients with chronic liver disease $(O)$. Both parameters have been normalised for body weight. 


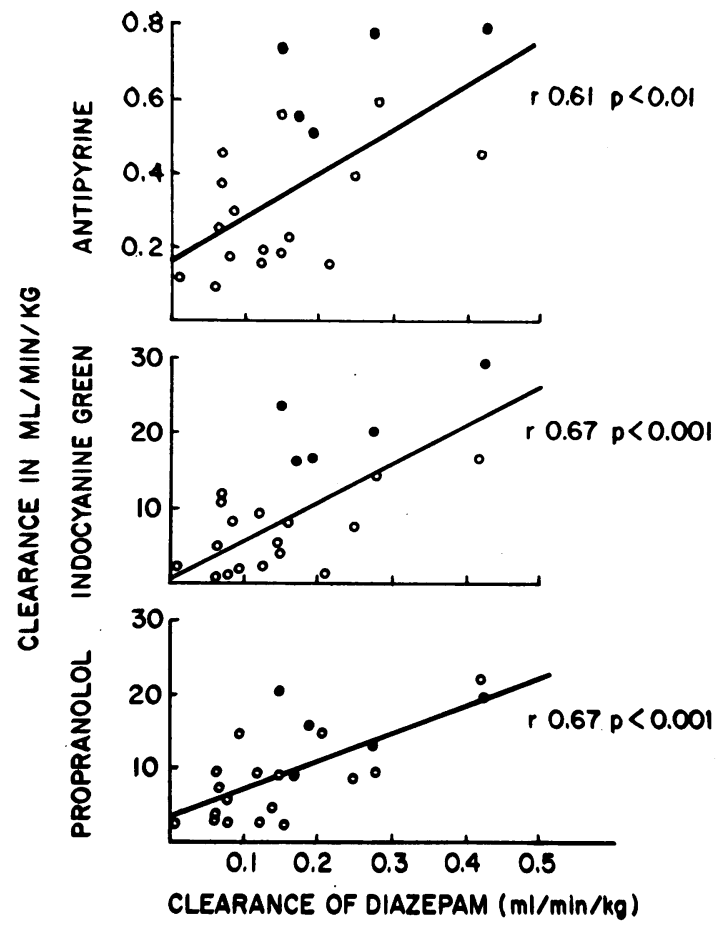

Fig. 7 The relationships between the plasma clearance of diazepam and the whole blood clearance of antipyrine, indocyanine green, and d-propranolol in five normal subjects $(\odot)$ and 17 patients with chronic liver disease (O). Clearances have been normalised for body weight.

indicating that liver disease increased the sensitivity to the effects of diazepam when administered on a per kilogram body weight basis. Using the serum albumin as a measure of liver function, the relationship between serum albumin and the dose of diazepam administered (Fig. 1) suggested that the increased sensitivity to diazepam was dependent on the degree of impairment of hepatic function. This study has investigated the EEG response and kinetics of diazepam in order to ascertain whether the reduction in dose requirements was due to a change in cerebral sensitivity to diazepam or to chances in drug disposition.

The mean dominant frequency (MDF) and slow wave index (SWI) are two EEG parameters which provide a quantitative sensitive index of slow wave EEG activity characteristic of developing hepatic delerium (Bickford and Butt, 1955; Laidlaw and Read, 1963) with changes which often precede objective clinical signs. The MDF, which is derived from frequencies between $2-14 \mathrm{H}_{\mathrm{z}}$ with greater than average abundance, and SWI, which measures relative and absolute activity at 2 to $3 \mathrm{~Hz}_{\mathrm{z}}$ both correlated with the serum albumin before drug administration (Fig. 2). Thus, subjects with impaired hepatic function had demonstrable changes in their baseline EEGs. During the diazepam administration there was a reduction in MDF and an increase in SWI in parallel with the clinical response. The changes in normal subjects were minimal, while patients with impaired hepatic function, particularly those with a history of hepatic encephalopathy, had the greatest change in both MDF and SWI (Fig. 3, Table 2). It is unlikely that the changes induced in the EEG were specific for diazepam, as similar changes have been reported in patients with chronic liver disease receiving diuretics without adequate potassium supplements (Read et al., 1954), after administration of phenothiazines (Read et al., 1969) and after administration of monamine oxidase inhibitors (Morgan and Read 1972). Previous observations of EEG changes induced by diazepam in patients with liver disease have demonstrated a mild increase in fast wave activity. However, in this study, the EEG was measured only one hour after a small fixed dose, rather than at the time of maximal response after a dose adequate to induce sedation (Murray-Lyon et al., 1971).

A reduction in the MDF and an increase in the SWI are thought to indicate disturbance of subcortical structure function, but their physiological influence is uncertain (Sherlock et al., 1954). Previous studies have noted that maximal changes in these parameters occur at the time of maximal sedation or coma (Laidlaw and Read, 1961) suggesting a causative role between EEG changes and sedation. It is of interest that diazepam induced a similar degree of sedation in normal subjects and patients with liver disease, yet there were marked differences in their EEGs. Therefore the relationship between slow wave EEG activity and sedation is more likely to be indirect.

After intravenous administration of diazepam to rats and guinea-pigs, cerebral concentrations are considerably higher than plasma concentrations and vary with subsequent time; however, the ratio of cerebral to blood concentration that induces anticonvulsant activity in these two species remains constant (Garattini et al., 1973). Thus, the plasma concentrations measured in this study would be expected to be in equilibrium with drug at the receptor site in the brain. In spite of differences in dose, the plasma concentrations at the end of the diazepam infusion were similar between normal subjects and patients with chronic liver disease (Table 3). These concentrations were associated with similar clinical responses but clear-cut differences in slow wave EEG activity in patients with chronic liver disease, particularly those with a previous 
history of PSE. This strongly suggests that the EEG changes were due to an increase in cerebral sensitivity to diazepam. The reason for this altered sensitivity remains unknown. It is possible that diazepam has a synergistic effect on another toxic agent such as ammonia, or that the response to diazepam might be influenced by the presence of a 'false neurotransmitter' (Fischer and Baldessarini, 1971). A further possibility is that previous hepatic encephalopathy induced persistent changes in cerebral function, altering its response to diazepam (Laidlaw and Read, 1963).

During a constant infusion of diazepam, there is rapid delivery of large quantities of drug into the vascular space, while simultaneously drug is being rapidly distributed to the tissues. The initial decline of the plasma concentration time curve indicates the rapid rate of these early distributional changes. The demonstration that regional cerebral diazepam concentrations correlate with regional variations in blood flow in the cat (Morselli et al., 1973) suggests that this early distribution is largely determined by regional blood flow distribution. Variations in early distribution due to flow limitations reasons may well explain why patients with chronic liver disease receiving smaller doses of diazepam had similar plasma concentrations at the end of the infusion. However, part of the explanation might also be due to the smaller volumes of distribution observed with subjects receiving smaller doses of diazepam (Fig. 5) resulting in a higher plasma concentration per dose ratio. The reason for the dose-dependent volume of distribution remains unknown; it is uncertain whether it is a function of diazepam kinetics or of liver disease. However, this relationship has obscured any possible relationship between age and volume of distribution (Klotz et al., 1975). Furthermore, it explains why the volume of distribution tended to decrease in liver disease in this study (Table 3) in contrast with the increases in volume of distribution observed by Klotz et al. (1975), when a constant dose protocol was used.

After the initial distribution phase, plasma concentrations tended to have variable trough and peak levels between two to 10 hours before entering a terminal exponential decline (Fig. 4). Similar results have previously been noted (De Silva et al., 1966; Van de Kleijn et al., 1971), but were not observed by Klotz et al. (1975). The assays used in all these studies were specific for the parent drug and concentrations were well within assay sensitivity. One explanation for this variation would be an enterohepatic recycling of drug; however, insignificant amounts of diazepam or desmethyl diazepam were recovered from bile in man (Klotz et al., 1975). An alternative hypothesis would be that plasma concentration could alter because drug was redistributed by changes in regional blood perfusion induced by exercise. Subjects in this study were allowed normal ward activities two hours after drug administration.

In man, diazepam is extensively but slowly metabolised in the liver, initially to $\mathrm{N}_{1}$-desmethyldiazepam and to a lesser extent to $\mathrm{N}_{1}$-methyloxazepam. These metabolites are further metabolised to oxazepam, which is finally conjugated and excreted in the urine (Schwartz et al., 1965; Marcucci et al., 1970). The efficiency of the overall drug eliminating mechanism is most easily quantitated by total drug clearance. It has previously been demonstrated that drug clearance is depressed in patients with chronic alcholic liver disease (Klotz et al., 1975); however, in this study of only nine patients, clearance did not correlate with any of the indices of hepatic function. In the present study, with a larger number of patients, there was a similar decrease in clearance; in addition, there was a significant correlation between diazepam clearance and the serum albumin (Fig. 6). The serum albumin provides an index of the ability of the liver to synthesise plasma proteins which also correlates with the elimination of other drugs (Levi et al., 1968, Mawer et al., 1972, Branch et al., 1973, Andreason et al., 1974). Interestingly, the patients in this study also participated in a further study in which antipyrine, d-propranolol and indocyanine green were administered in single bolus doses on separate occasions (Branch et al., 1976a, b). In spite of variability in the data, there were significant correlations between the clearance of diazepam and antipyrine-a drug with a similar low clearance but a different route of metabolism-and the two high clearance drugs with different mechanisms of elimination, propranolol by hydroxylation and indocyanine green by active transport to bile, without undergoing metabolism (Fig. 6). The implications of a parallel reduction in clearance of high and low clearance drugs have been more fully discussed elsewhere (Branch et al., 1976b; Branch and Shand, 1976). These interdrug clearance correlations do suggest that in chronic liver disease impairment of hepatic function can be expected to reduce the clearance of most drugs which are eliminated by the liver irrespective of the mechanism of drug elimination, and furthermore that the degree of impairment appears to be quantitatively similar. These observations would be in agreement with the hypothesis that chronic liver disease is associated with a reduction in mass of normally functioning hepatic tissue.

In conclusion, the serum albumin has provided a useful index of liver function for anticipating the 
response to diazepam administration. For example, a patient with severe chronic liver disease with a low serum albumin would be expected to have baseline abnormalities in MDF and SWI, require the smallest dose of diazepam to induce a defined clinical response, to have large changes in MDF an SWI at this endpoint, and finally to have impaired elimination of many drugs, including diazepam.

The authors would like to acknowledge the expert technical help of Mrs A. Denning and financial and technical support from Dr M. Duffus of Roche Ltd. U.K.

\section{References}

Andreasen, P. B., Ranek, L., Statland, B. E., and Tygstrup, N. (1974). Clearance of antipyrine-dependence of quantitative liver function. European Journal of Clinical Investigation, 4, 129-134.

Bickford, R. G., and Butt, H. R. (1955). Hepatic coma: the electroencephalographic pattern. Journal of Clinical Investigation, 34, 790-799.

Branch, R. A., Herbert, C. M., and Read, A. E. (1973). Determinants of serum antipyrine half-lives in patients with liver disease. Gut, 14, 569-573.

Branch, R. A., James, J., and Read, A. E. (1976a). A study of factors influencing drug disposition in chronic liver disease using the model drug (t)-propranolol. British Journal of Clinical Pharmacology, 3, 243-249.

Branch, R. A., James, J., and Read, A. E. (1976b). The clearance of antipyrine and indocyanine green in normal subjects and patients with chronic liver disease. Clinical Pharmacology and Therapeutics.

Branch, R. A., and Shand, D. G. (1976). Propranolol disposition in chronic liver disease: A physiological approach. Clinical Pharmacokinetics. 1, 264-279.

Brodie, B. B., Axelrod, J., Soberman, R., and Levy, B. B. (1949). The estimation of antipyrine in biological materials. Journal of Biological Chemistry, 179, 25-28.

Caesar, J., Shaldon, S., Chiandussi, L., Guevara, L., and Sherlock, S. (1961). The use of indocyanine green in the measurement of hepatic blood flow and as a test of hepatic function. Clinical Science and Molecular Medicine, 21, 43-57.

De Silva, J. A. F., Koechlin, B. A., and Bader, G. (1966). Blood level distribution patterns of diazepam and its major metabolite in man. Journal of Pharmaceutical Sciences, 55, 692-702.

Fischer, J. E., and Baldessarini, R. J. (1971). False neurotransmitters and hepatic failure. Lancet, 2, 75-79.

Garattini, S., Marcuci, F., Mosselli, P. L., and Mussini, L. (1973). The significance of measuring blood levels of benozodiazepines. In Biological Effects of Drugs in Relation to their Plasma Concentrations, pp. 211-225. Edited by D. S. Davies, and B. N. C. Prichard, University Park Press: Baltimore.
Kleijm, Van der E., Van Dossum, J. M., Muskens, E. J. M., and Rijntjes, N. V. M. (1971). Pharmacokinetics of diazepam in dogs, mice and humans. Acta Pharmacologica Toxicologica, 29, suppl 3, 109-127.

Klotz, U., Avant, G. R., Hoyumpa, A., Schenker, S., and Wilkinson, G. R. (1975). The effects of age and liver disease on the disposition and elimination of diazepam in adult man. Journal of Clinical Investigation, 55, 347-359.

Laidlaw, J., and Read, A. E. (1961). The electroencephalographic diagnosis of manifest and latent 'delirium' with particular reference to that complicating hepatic cirrhosis. Journal of Neurology, Neurosurgery, and Psychiatry, 24, 58-70.

Laidlaw, J., and Read, A. E. (1963). The EEG in hepatic encephalopathy. Clinical Science and Molecular Medicine, 24, 109-120.

Levi, A. J., Sherlock, S., and Walker, D. (1968). Phenylbutazone and isoniazid metabolism in patients with liver disease in relation to previous drug therapy. Lancet, 1 , 1275-1279.

Marcucci, F., Fanelli, R., Mussini, E., and Garrattini (1970). Further studies on species difference in diazepam metabolism. European Journal of Pharmacology, 9, 253-256.

Mawer, G. E., Miller, N. E., and Turnburg, L. A. (1972). Metabolism of amylobarbitone in patients with chronic liver disease. British Journal of Pharmacology, 44, 549-560.

Morselli, P. L., Cassano, G. B., Placidi, G. F., Muscettola, B. G., and Rizzo, M. (1973). Kinetics of the distribution of $C^{14}$ diazepam and its metabolites in various areas of cat brain. In The Benzodiazepines, pp. 129-143. Edited by S. Garrattini, E. Mussini, and L. O. Randall. Raven Press: New York.

Morgan, M. H., Bolton, C. H., Morris, J. S., and Read, A. E. (1974). Medium chain triglycerides and hepatic encephalopathy. Gut, 15, 180-184.

Morgan, M. H., and Read, A. E. (1972). Antidepressants and liver disease. Gut, 13, 697-701.

Murray-Lyon, I. M., Young, J., Parkes, J. D., Knill-Jones, R. P., and Williams, R. (1971). Clinical and electroencephalographic assessment of diazepam in liver disease. British Medical Journal, 4, 265-266.

Read, A. E., Laidlaw, J., Haslam, R. M., and Sherlock, S. (1954). . Neuropsychiatric complications following chlorothiazide therapy in patients with hepatic cirrhosis: possible relation to hypokalaemia. Clinical Science and Molecular Medicine, 18, 409-412.

Read, A. E., Laidlaw, J., and McCarthy, C. F. (1969). Effects of chlorpromazine in patients with hepatic disease. British Medical Journal, 3, 497-499.

Schwartz, M. A., Koechlin, B. A., Postma, E., Palmer, S., and Krol, G. (1965). Metabolism of diazepam in rat, dog and man. Journal of Pharmacology and Experimental Therapeutics, 149, 423-435.

Shand, D. G., Nuckolls, E. M., and Oates, J. A. (1970). Plasma propranolol levels in adults with observations in four children. Clinical Pharmacology and Therapeutics, 11, 112-120.

Sherlock, S., Summerskill, W. H. J., White, L. P., and Phear, I. A. (1954). Portal-systemic encephalopathy: neurological complications of liver disease. Lancet, 2, 453-457. 